\title{
Characterization of Bottom and Fly Ashes Generated Co-incineration of Biomass with Automotive Shredder Residue
}

\author{
Muhamad Fazli Othaman ${ }^{*}$, Sulastri Sabudin, and Mohd Faizal Mohideen \\ Centre for Energy and Industrial Environment Studies (CEIES), Department of Energy and \\ Thermofluid Engineering, Faculty Of Mechanical and Manufacturing Engineering Universiti Tun \\ Hussien Onn Malaysia
}

\begin{abstract}
One of the viable techniques to reduce land filling of automotive shredder residue is by co-incinerating them with biomass. This study focuses on characterization of bottom and fly ashes produced from the coincineration of the automotive shredded residue with oil palm biomass. The co-incineration was carried out in a pilot-scale fluidized bed incinerator. The oil palm biomass used was oil palm shell while the automotive shredded residue was obtained from a local recycling company. The characterization was done based on particle size distribution, morphology (SEM analysis) and chemical composition (EDS analysis). In term of chemical composition the ashes contain C (Carbon), O (Oxygen), Si (Silicon), K (Potassium), Ca (Calcium) and $\mathrm{Fe}$ (Ferum.
\end{abstract}

\section{Introduction}

Automotive shredder residue are basically waste obtained from end-of-life vehicles (ELV) which was unrecyclable and most from non-metallic parts[1]. These waste from ELV kept increasing every year with the growth of automotive industry. Annually the total amount of vehicles registration increases about $12 \%$ each year over the period of 5 years in Malaysia. It being estimated that in year 2020 around 31 million will be on Malaysian road [2]. These non-metal component from vehicles originates from various parts of the vehicle, mainly the dashboard, car seat, car carpet and car bumper. This various part mostly made up from plastic and PVC and most of these elements cannot be recycled nor reused, it will usually be disposes in landfills [3]. However, the increasing concern regarding the environmental issues regarding landfills has resulted more stringent regulations imposed by the local authorities and governments as landfilling affects directly the ecosystem, environment and population [4].

One of the viable techniques in handling automotive shredder residue (ASR) is by incineration and co-incineration with other wastes $[3,4]$. Both of this processes may reduce significantly the total amount of ASR that is landfilled and thus ease the environmental impact. However, both incineration and co-incineration process produces fly ash and bottom ash which may contain concentrated amount of hazardous substance such as dioxin.

* Corresponding author: fazli.othaman@gmail.com 
According to $[5,6]$ biomass is one of the energy resource that was high potential to mitigate emission of greenhouse gases [5]. Furthermore from composition of biomass can reduces the carbon monoxide emission [6]. Significantly for incineration, fluid bed combustion technology have proven for high combustion efficiency and these technology have advantage of burning different type of fuel such as solid fuel in a combustor [7]. These technology increase air-fuel contact and result in the complete combustion can occur. Many researcher reported obtaining combustion efficiency up to $99 \%$ [8-10]. Moreover, with the higher combustion efficiency these process can also reduce the emission of $\mathrm{NO}_{\mathrm{x}}$ [11]. Thus, in this study, the ASR and Oil Palm Shell (OPS) were blended together in the co-incineration process. This paper reports the characteristics of bottom and fly ashes generated from coincineration process of oil palm biomass and automotive waste. The characteristic of bottom ash taken from combustion chamber and fly ash came out from the cyclone were reported in the following section.

Table 1. Composition of End Life Vehicle [3].

\begin{tabular}{|l|c|}
\hline Material & \% of total mass \\
\hline Ferrous metal & $65.4-71.0$ \\
\hline Non- Ferrous metal & $7.0-10.0$ \\
\hline Plastics & $7.0-9.3$ \\
\hline Rubber & $4.0-5.6$ \\
\hline Glass & $2.9-3.0$ \\
\hline Fluid & $0.9-6.0$ \\
\hline Battery & $1.0-1.1$ \\
\hline Process polymers & $1.0-1.1$ \\
\hline Electrical/electronic & $0.4-1.0$ \\
\hline Other & $1.0-5.9$ \\
\hline
\end{tabular}

\section{Methodology}

\subsection{Fuel preparation}

The fuel that used in this experiment is oil palm shell biomass from palm oil tree and the automotive shredded residue that came from end-life-vehicle (ELV) which cannot be recycle. For resident particles in the fluidized bed system, sand particle were used. The sand sieving range is between $650-850 \mu \mathrm{m}$, and the average sand diameter was $750 \mu \mathrm{m}$. The sieving was done using mechanical sieving
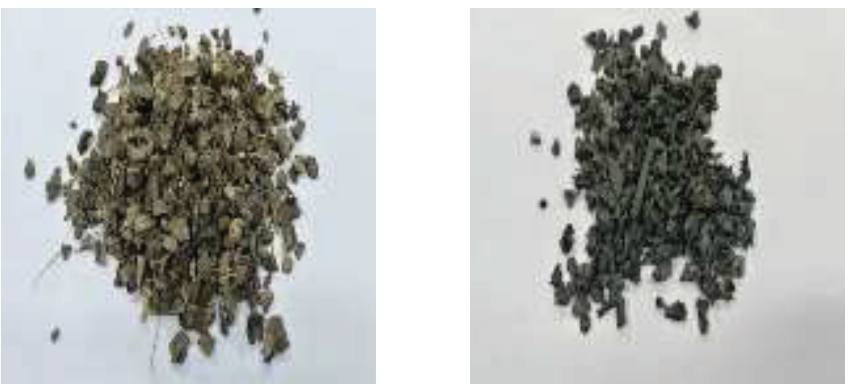

Fig. 1. (a) Oil palm shell and (b) automotive shredded residue 


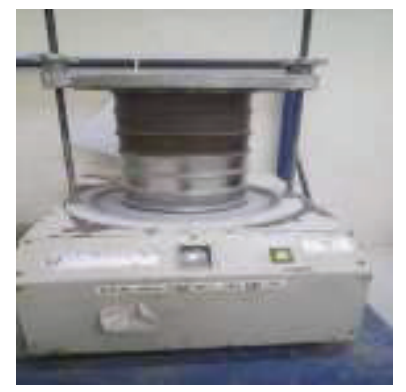

Fig. 2. Sieving mechanical shaking

\subsection{Experimental setup}

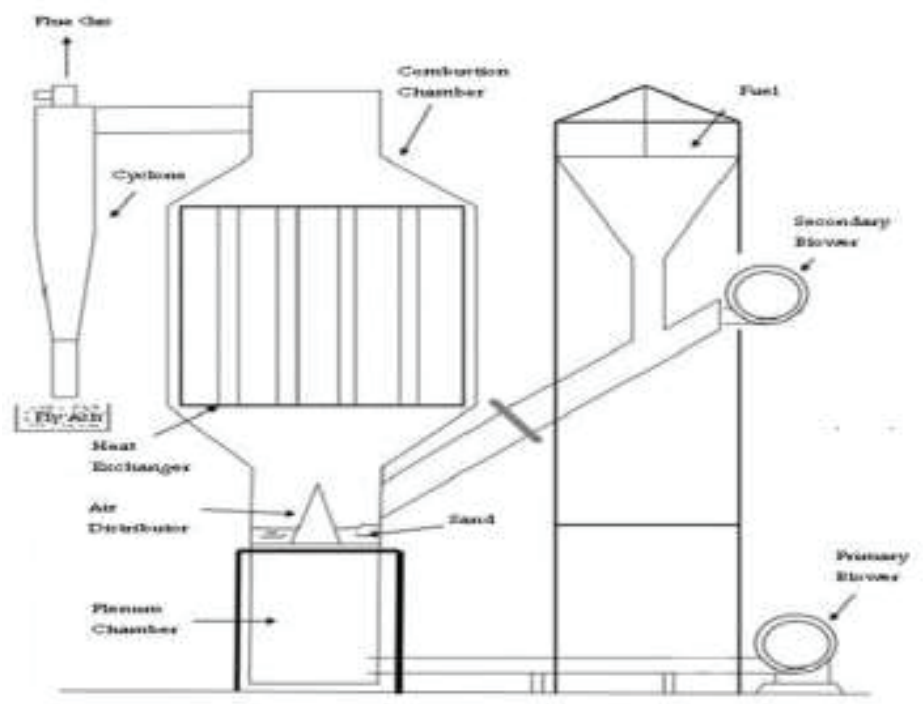

Fig. 3. Schematic diagram for experiment

Fig. 3 shows the schematic diagram for the experiment setup. Initially the resident material (sand) was preheated of at $600^{\circ} \mathrm{C}$ for about 20 minutes. Upon reaching this temperature, the fuel mixture (OPS and ASR) will be fed to the combustion chamber until incineration takes place steadily. Secondary air was also introduced into the bed upon attaining stable incineration process, temperature and emission gaseous produced were recorded using data logger as well as gas analyzer. Bottom ash was also collected from the cyclone and cooled before labelled. At the end of the co-incineration process, the system was allowed to cool for few hours before the bottom ash were recorded. Both of this ashes were characterized by particle size distribution, morphology and chemical composition. The particle size distribution was obtained by sieving through 6 sizes, $355 \mu \mathrm{m}, 250 \mu \mathrm{m}, 212 \mu \mathrm{m}, 180 \mu \mathrm{m}$, $125 \mu \mathrm{m}$, and $90 \mu \mathrm{m}$. Scanning Electron Microscope (SEM) was used to observe external morphology and crystalize structures while Energy Dispersive X-ray (EDS) was used to obtain the chemical composition. 


\section{Results and discussion}

\subsection{Particle size distribution}

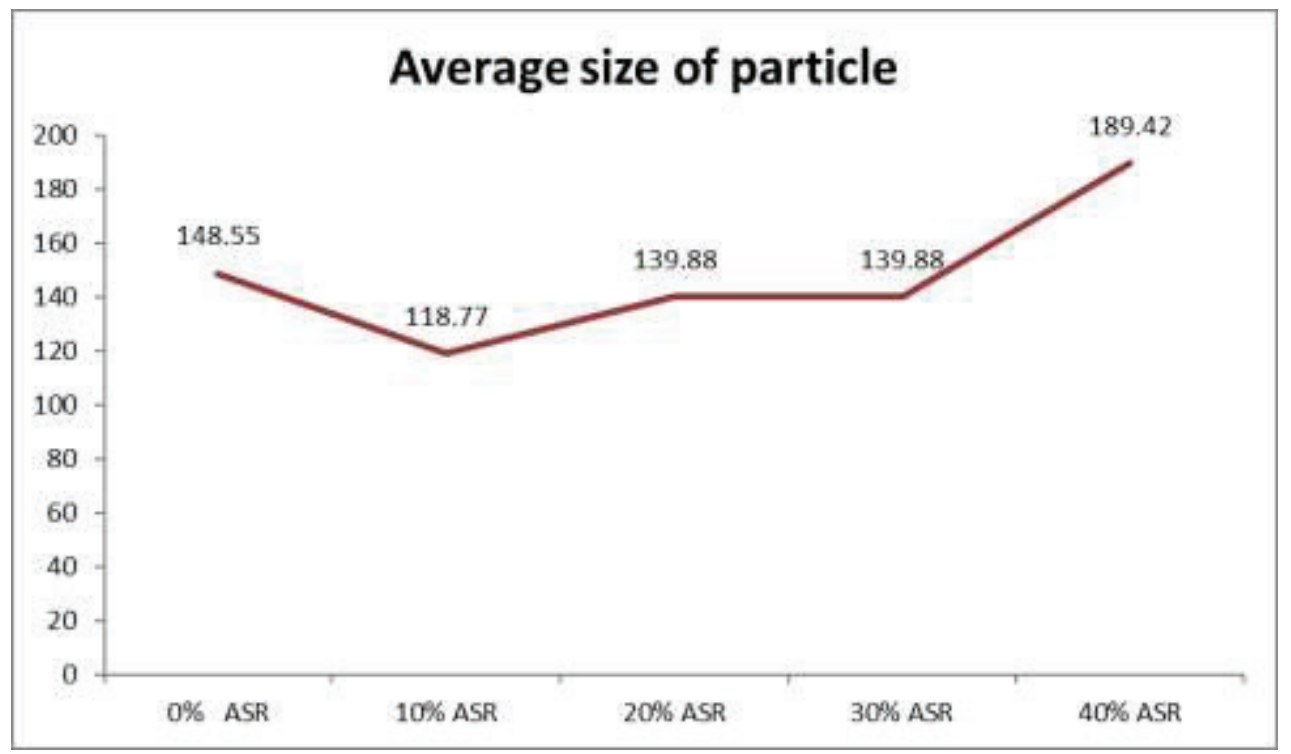

Fig.4. Average size particle size of fly ash

Referring to Fig.4, the average size of fly ash particles were between $118 \mu \mathrm{m}$ to $190 \mu \mathrm{m}$. The sizes were found to slightly increase with the amount of ASR in the fuel mixture. The average fly ash particle sizes for $0 \%, 10 \%, 20 \%, 30 \%$ and $40 \%$ ASR were: $148.55 \mu \mathrm{m}, 118.77 \mathrm{~mm}$, $139.88 \mathrm{~mm}, 139.88 \mathrm{~mm}$ and $189.42 \mathrm{~mm}$ respectively. For bottom ash, the shapes were irregular and the particle sizes vary from $1 \mathrm{~mm}$ to $10 \mathrm{~mm}$. The amount of ASR has little influence on the bottom ash. The morphology of the fly ash particles were shown via SEM as in the following section:

\subsection{Morphology}

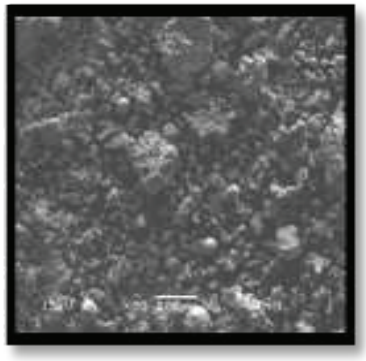

(a) $10 \% \mathrm{ASR}$

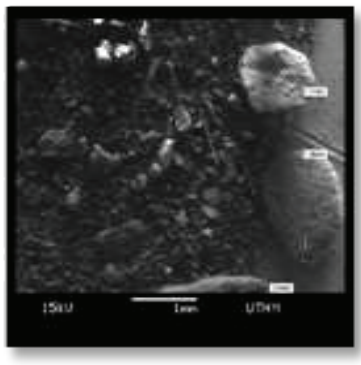

(b) $20 \% \mathrm{ASR}$ 


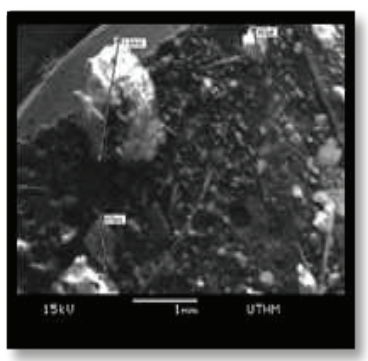

(c) $30 \%$ ASR

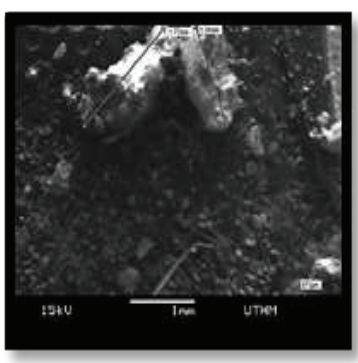

(d) $40 \%$ ASR

Fig.5. SEM images for fly ash with different ASR content

In general, the fly ash particle size increased with amount of ASR. It was also found that the fly ash particles do not have a common feature and the shape was irregular and diverse. On the other hand, the fly ash from 0\% ASR particle 100\% OPS is given in Fig. 6 while the bottom ash for OPS and fuel mixture with ASR is shown in Fig. 7 and Fig. 8.

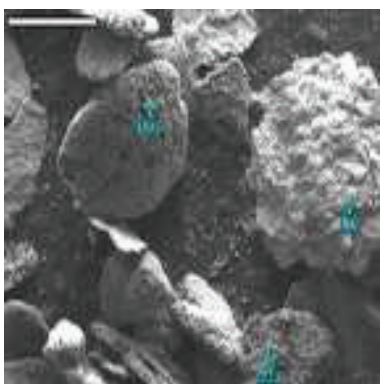

Fig.6. SEM image capture for OPS fly ash sample ( $0 \%$ ASR)

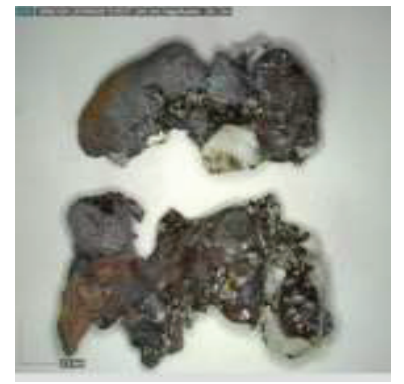

Fig.7. Bottom ash sample of OPS

According to both Fig. 7 and 8 above, sample 2 of bottom ash OPS also has irregular shape and doesn't have a fixed shape of bottom ash. Both of this samples shows that, the bottom ash of OPS doesn't have a fixed shape and has an irregular shape. 


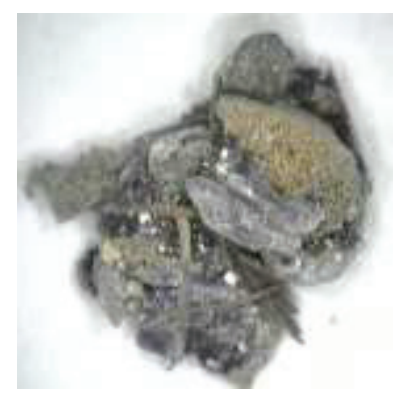

Fig.8. Bottom ash sample of OPS

\subsection{Chemical composition}

Table 2. Chemical composition in fly ash with certain ASR content

\begin{tabular}{|c|c|c|c|c|c|c|c|c|}
\hline \multirow{2}{*}{ ?. } & \multicolumn{8}{|c|}{ Elements that exist (\%) } \\
\hline & \multicolumn{2}{|r|}{10} & \multicolumn{2}{|r|}{20} & \multicolumn{2}{|c|}{30} & \multicolumn{2}{|r|}{40} \\
\hline \multirow[t]{8}{*}{1} & (C) & 11388.14 & (O) & 3561.73 & (C) & 974.10 & $(\mathrm{O})$ & 11391.27 \\
\hline & $\left(\mathrm{S}_{\mathrm{i}}\right)$ & 2296.05 & $(\mathrm{Fe})$ & 13201.09 & (O) & 26435.98 & $(\mathrm{Fe})$ & 16888.12 \\
\hline & $(\mathrm{K})$ & 6254.20 & $(\mathrm{Al})$ & 14262.04 & $(\mathrm{Mg})$ & 18409.72 & $(\mathrm{Zn})$ & 486.70 \\
\hline & (Ca) & 1495.70 & $(\mathrm{Mg})$ & 1236.34 & (Si) & 27171.50 & $(\mathrm{Mg})$ & 1381.64 \\
\hline & $(\mathrm{O})$ & 416.29 & $(\mathrm{Si})$ & 12921.51 & $(\mathrm{~S})$ & 8712.88 & $(\mathrm{Si})$ & 1955.39 \\
\hline & & & & & (Ca) & 14311.07 & $(\mathrm{~S})$ & 1045.01 \\
\hline & & & & & & & $(\mathrm{K})$ & 1568.20 \\
\hline & & & & & & & (Ca) & 1064.96 \\
\hline \multirow[t]{8}{*}{2} & (C) & 12930.24 & (O) & 11442.04 & (C) & 1625.09 & $(\mathrm{O})$ & 17138.21 \\
\hline & $\left(\mathrm{S}_{\mathrm{i}}\right)$ & 3730.70 & (C) & 515.47 & (O) & 35193.30 & $(\mathrm{Fe})$ & 13298.34 \\
\hline & $\left(\mathrm{Mg}_{\mathrm{g}}\right)$ & 420.36 & $(\mathrm{Fe})$ & 17177.83 & $(\mathrm{Fe})$ & 1607.53 & $(\mathrm{Mg})$ & 6613.23 \\
\hline & $(\mathrm{K})$ & 1289.80 & $(\mathrm{Si})$ & 506.00 & $(\mathrm{Mg})$ & 29111.15 & $(\mathrm{Si})$ & 10270.09 \\
\hline & $\left(\mathrm{C}_{\mathrm{a}}\right)$ & 888.26 & & & $(\mathrm{Si})$ & 40044.45 & $(\mathrm{Ca})$ & 957.25 \\
\hline & (O) & 1761.96 & & & (S) & 2099.40 & $(\mathrm{Fe})$ & 13298.34 \\
\hline & & & & & $(\mathrm{K})$ & 2083.84 & & \\
\hline & & & & & $(\mathrm{Ca})$ & 3813.42 & & \\
\hline \multirow[t]{8}{*}{3} & (C) & 86.76 & (C) & 1511.95 & (C) & 4607.29 & (O) & 17910.92 \\
\hline & $\left(\mathrm{S}_{\mathrm{i}}\right)$ & 186.79 & (O) & 20559.12 & (O) & 436.47 & $(\mathrm{Fe})$ & 12053.11 \\
\hline & $\left(\mathrm{Mg}_{\mathrm{g}}\right)$ & 105.23 & $(\mathrm{Fe})$ & 10301.90 & $(\mathrm{Mg})$ & 446.37 & $(\mathrm{Mg})$ & 6160.22 \\
\hline & $(\mathrm{Fe})$ & 2130.39 & $(\mathrm{Mg})$ & 3935.38 & (Si) & 775.58 & $(\mathrm{Si})$ & 8892.45 \\
\hline & $(\mathrm{K})$ & 169.88 & $(\mathrm{Si})$ & 6550.09 & $(\mathrm{~K})$ & 201.21 & $(\mathrm{~K})$ & 819.80 \\
\hline & $\left(\mathrm{C}_{\mathrm{a}}\right)$ & 133.64 & (S) & 7899.74 & (Ca) & 379.45 & $(\mathrm{Ca})$ & 755.35 \\
\hline & $(\mathrm{O})$ & 613.89 & $(\mathrm{~K})$ & 6440.19 & & & & \\
\hline & & & (Ca) & 3740.85 & & & & \\
\hline
\end{tabular}

The table indicates the chemical composition in the fly ash with particular amount of ASR. These chemical composition was obtained by scrutinizing 3 points which were randomly selected to indicate the percentage of elements exist all the samples. For fly ash sample containing $10 \%$ ASR, higher percentage of silicon ( $\mathrm{Si}$ ) was observed while for $20 \%$ ASR, 
oxygen (O) was found to be dominant. As for fly ash sample with 30\% ASR, higher percentages of Si was again found and finally for fly ash with 40\% ASR, O content was higher. Silicon can be classified as gothic metal which is not harmful for the environment while oxygen can be classified as death metal. Both of these elements have higher percentages among blending ratio with the presence of ASR. From the table above, it also indicated that value of percentage ferum elements at $40 \%$ ASR is highest among other blending ratio. Since the ferum is in classic heavy metal classes, the sample in $40 \%$ of ASR is hazardous among others by comparing the value of percentages of counts mass. Thus, blending ratio of $10 \%$ ASR, 20\% ASR and 30\% ASR is safely landed for disposal while for $40 \%$ ASR blending ratio were not safe for disposal due to the present of ferum elements.

Table 3. Elements that exist in fly ash OPS

\begin{tabular}{|c|c|c|}
\hline \multirow{2}{*}{ POINT } & \multicolumn{2}{|c|}{ ELEMENT PRESENT } \\
\cline { 2 - 3 } & \multicolumn{2}{|c|}{ OPS } \\
\hline \multirow{2}{*}{} & $(\mathrm{C})$ & 5811.08 \\
& $(\mathrm{O})$ & 328.96 \\
& $(\mathrm{Si})$ & 147.96 \\
& $(\mathrm{~K})$ & 656.96 \\
& $(\mathrm{Ca})$ & 309.42 \\
\hline $\mathbf{2}$ & $(\mathrm{C})$ & 104.73 \\
& $(\mathrm{O})$ & 662.37 \\
& $(\mathrm{Fe})$ & 99.98 \\
& $(\mathrm{Ca})$ & 2325.33 \\
\hline \multirow{3}{*}{} & $(\mathrm{C})$ & 602.36 \\
& $(\mathrm{O})$ & 586.90 \\
& $(\mathrm{Si})$ & 2057.47 \\
& $(\mathrm{~K})$ & 552.95 \\
& $(\mathrm{Ca})$ & 418.39 \\
\hline
\end{tabular}

According to the table of elements that exists in fly ash of OPS above, the existing elements were Carbon (C), Oxygen (O), Silicon (Si), Potassium (K), Calcium (Ca) and Ferum (Fe). There are 3 randomly point was selected to examine the composition of ashes. In each of point consist different of percentage in each elements exists. From the table above indicated that carbon elements have a higher percentage of count mass with $5811.08 \%$. Element that have least percentage of mass count was ferum with $99.98 \%$.

Table 4. Element that exist in bottom ash data

\begin{tabular}{|l|l|l|l|}
\hline \multicolumn{3}{|l|}{ ELEMENT PRESENT (\%) } \\
\hline \multicolumn{3}{|l|}{ OPS + ASR } & OPS \\
\hline$(\mathrm{O})$ & 1987.54 & $(\mathrm{O})$ & 31158.14 \\
$(\mathrm{Mg})$ & 160.64 & $(\mathrm{Fe})$ & 39543.15 \\
$(\mathrm{Si})$ & 721.63 & $(\mathrm{Al})$ & 14839.54 \\
& & $(\mathrm{Si})$ & 9707.14 \\
& & & \\
\hline
\end{tabular}

In the table above, list of elements present in both of the bottom ash samples were presented. For sample mixture of OPS and ASR indicated only three elements which were Oxygen (O), Magnesium (Mg) and Silicon (Si) with Silicon in higher percentage of counts mass. For other bottom ash sample of OPS, the findings indicated four elements existed namely Oxygen $(\mathrm{O})$, Ferum (Fe), Aluminium (Al) and Silicon (Si) with Ferum in higher percentages of mass count. 


\section{Conclusion}

From the experimental results, it can be concluded that the objective of the scope was achieved. The experiments were carried out by several characterizations. There are four characterizations were analyzed in order to determine whether both of ashes were safe for disposal or not. First characterization was particle size distribution to determine average size of particle.as the result reviewed that increasing of percentage of ASR in blending ratio will increase the average size of particle. Second characterization was morphology purposely to compare the shape among of blending ratio and it was indicated that both of ashes was in irregular shape, spherical shape and doesn't have fixed shape. Third characterization was chemical composition is to determine the percentage of elements exist in each of bottom ash and fly ash according to their blending ratio. Lastly, a heavy metal test characterization is to identify whether the sample ash contain heavy metal elements and it's concentration.

First characterization was particle size distribution to determine average size of particle.as the result reviewed that increasing of percentage of ASR in blending ratio will increase the average size of particle. Second characterization was morphology purposely to compare the shape among of blending ratio and it was indicated that both of ashes was in irregular shape, spherical shape and doesn't have fixed shape. Third characterization is chemical composition is to determine the percentage of elements exist in each of bottom ash and fly ash according to their blending ratio. Results indicated that the percentage of ASR in blending ratio will increase the concentration of heavy metal elements.

\section{Acknowledgement}

The authors would like to express our deepest gratitude to Centre Graduate Studies (CGS) Universiti Tun Hussein Onn Malaysia (UTHM) for funding this research via Contract Research Fund, vot no. U 525 as well as providing the related equipment for our study.

\section{References}

1. L. Morselli, A. Santini, F. Passarini, I. Vassura, Automotive shredder residue (ASR) characterization for a valuable management, Waste Manag., vol. 30, no. 11, pp. 222834, (2010)

2. M. Azmi, M. Zameri, M. Saman, S. Sharif, 5 . 6 Proposed framework for End-Of-Life vehicle recycling system implementation in Malaysia, pp. 187-193, (2013).

3. I.Vermeulen, J.Van Caneghem, C.Block, J.Baeyens, C.Vandecasteele, Automotive shredder residue (ASR): reviewing its production from end-of-life vehicles (ELVs) and its recycling energy or chemicals' valorisation, Journal of Hazardous Materials, 190(1), pp.8-27, (2011)

4. A. Nzihou, N. J. Themelis, M. Kemiha, Y. Benhamou, Dioxin emissions from municipal solid waste incinerators ( MSWIs ) in France, Waste Manag, vol. 32, no. 12, pp. 22732277, (2012)

5. F. Okasha, G. Zaater, M. Awad, E. Zeidan, Co-combustion of biomass and gaseous fuel in a novel configuration of fluidized bed : Combustion characteristics FUEL, vol. 133, pp. 143-152, 2014.

6. M. Fazli othaman, S. Sabudin, M. Faizal Batcha, A Short Review on Biomass ThermoChemical Conversion : Recent Advances, vol. 8, no. 6, pp. 2494-2499, (2017).

7. M. Varol, A. T. Atimtay, Effect of biomass-sulfur interaction on ash composition and agglomeration for the co-combustion of high-sulfur lignite coals and olive cake in a 
circulating fluidized bed combustor, Bioresour. Technol, vol. 198, pp. 325-331, (2015).

8. T. Madhiyanon, P. Sathitruangsak, S. Soponronnarit, Co-combustion of rice husk with coal in a cyclonic fluidized-bed combustor ( $\psi$-FBC), Fuel, vol. 88, no. 1, pp. 132-138, Jan. (2009).

9. P. Ninduangdee, V. I. Kuprianov, Combustion of oil palm shells in a fluidized-bed combustor using dolomite as the bed material to prevent bed agglomeration, Energy Procedia, vol. 52, pp. 399-409, 2014.

10. T. Madhiyanon, P. Sathitruangsak, S. Soponronnarit, Co-firing characteristics of rice husk and coal in a cyclonic fluidized-bed combustor ( $\Psi$-FBC) under controlled bed temperatures, Fuel, vol. 90, no. 6, pp. 2103-2112, Jun. (2011).

11. J. Van Caneghem, J, A. Brems, P. Lievens, C. Block, P. Billen, I. Vermeulen, R. Dewil, J. Baeyens, C. Vandecasteele, Fluidized bed waste incinerators: Design, operational and environmental issues, Prog. Energy Combust. Sci., vol. 38, no. 4, pp. 551-582, Aug. (2012). 